\title{
Peptide functionalized polyhydroxyalkanoate nanofibrous scaffolds enhance Schwann cells activity
}

Citation for published version (APA):

Masaeli, E., Wieringa, P. A., Morshed, M., Nasr-Esfahani, M. H., Sadri, S., van Blitterswijk, C. A., \& Moroni, L. (2014). Peptide functionalized polyhydroxyalkanoate nanofibrous scaffolds enhance Schwann cells activity. Nanomedicine-Nanotechnology Biology and Medicine, 10(7), 1559-1569. https://doi.org/10.1016/j.nano.2014.04.008

Document status and date:

Published: 01/10/2014

DOI:

10.1016/j.nano.2014.04.008

Document Version:

Publisher's PDF, also known as Version of record

Document license:

Taverne

Please check the document version of this publication:

- A submitted manuscript is the version of the article upon submission and before peer-review. There can be important differences between the submitted version and the official published version of record.

People interested in the research are advised to contact the author for the final version of the publication, or visit the DOI to the publisher's website.

- The final author version and the galley proof are versions of the publication after peer review.

- The final published version features the final layout of the paper including the volume, issue and page numbers.

Link to publication

\footnotetext{
General rights rights.

- You may freely distribute the URL identifying the publication in the public portal. please follow below link for the End User Agreement:

www.umlib.nl/taverne-license

Take down policy

If you believe that this document breaches copyright please contact us at:

repository@maastrichtuniversity.nl

providing details and we will investigate your claim.
}

Copyright and moral rights for the publications made accessible in the public portal are retained by the authors and/or other copyright owners and it is a condition of accessing publications that users recognise and abide by the legal requirements associated with these

- Users may download and print one copy of any publication from the public portal for the purpose of private study or research.

- You may not further distribute the material or use it for any profit-making activity or commercial gain

If the publication is distributed under the terms of Article $25 \mathrm{fa}$ of the Dutch Copyright Act, indicated by the "Taverne" license above, 


\title{
Peptide functionalized polyhydroxyalkanoate nanofibrous scaffolds enhance Schwann cells activity
}

\author{
Elahe Masaeli, $\mathrm{PhD}^{\mathrm{a}, \mathrm{b}, \mathrm{c}, *}$, Paul A. Wieringa, $\mathrm{MSc}^{\mathrm{c}}$, Mohammad Morshed, $\mathrm{PhD}^{\mathrm{a}}$, \\ Mohammad H. Nasr-Esfahani, $\mathrm{PhD}^{\mathrm{b}}$, Saeid Sadri, $\mathrm{PhD}^{\mathrm{d}}$, \\ Clemens A. van Blitterswijk, $\mathrm{PhD}^{\mathrm{c}}$, Lorenzo Moroni, $\mathrm{PhD}^{\mathrm{c}, * *}$ \\ ${ }^{\mathrm{a}}$ Department of Textile Engineering, Isfahan University of Technology, Isfahan, Iran \\ ${ }^{\mathrm{b}}$ Department of Cellular Biotechnology at Cell Science Research Center, Royan Institute for Biotechnology, ACECR, Isfahan, Iran \\ ${ }^{\mathrm{c}}$ Department of Tissue Regeneration, University of Twente, Enschede, The Netherlands \\ ${ }^{\mathrm{d}}$ Department of Electrical and Computer Engineering, Isfahan University of Technology, Isfahan, Iran
}

Received 1 September 2013; accepted 20 April 2014

\begin{abstract}
Interactions between Schwann cells (SCs) and scaffolds are important for tissue development during nerve regeneration, because SCs physiologically assist in directing the growth of regenerating axons. In this study, we prepared electrospun scaffolds combining poly (3hydroxybutyrate) (PHB) and poly (3-hydroxybutyrate-co-3-hydroxyvalerate) (PHBV) functionalized with either collagen I, H-Gly-Arg-GlyAsp-Ser-OH (GRGDS), H-Tyr-Ile-Gly-Ser-Arg-NH2 (YIGSR), or H-Arg-Asn-Ile-Ala-Glu-Ile-Ile-Lys-Asp-Ile-OH (p20) neuromimetic peptides to mimic naturally occurring ECM motifs for nerve regeneration. Cells cultured on fibrous mats presenting these biomolecules showed a significant increase in metabolic activity and proliferation while exhibiting unidirectional orientation along the orientation of the fibers. Real-time PCR showed cells cultured on peptide-modified scaffolds had a significantly higher neurotrophin expression compared to those on untreated nanofibers. Our study suggests that biofunctionalized aligned PHB/PHBV nanofibrous scaffolds may elicit essential cues for SCs activity and could serve as a potential scaffold for nerve regeneration.
\end{abstract}

From the Clinical Editor: Nanotechnology-based functionalized scaffolds represent one of the most promising approaches in peripheral nerve recovery, as well as spinal cord recovery. In this study, bio-functionalized and aligned PHB/PHBV nanofibrous scaffolds were found to elicit essential cues for Schwann cell activity, therefore could serve as a potential scaffold for nerve regeneration.

(c) 2014 Elsevier Inc. All rights reserved.

Key words: Schwann cells; Scaffold; Electrospinning; Peptide

Schwann cells (SCs) are currently being investigated as a component of nerve repair strategies because of their known ability to support nerve regeneration in both the central nervous system (CNS) and the peripheral nervous system (PNS), where

Statement of funding: Elahe Masaeli acknowledges Isfahan University of Technology (IUT) and the Ministry of Science, Research and Technology (MSRT, Iran) for the scholarship conferred to her and the financial support provided.

Conflicts of interest: Authors declare to have no conflicts of interest related to the work presented in this article.

*Correspondence to: E. Masaeli, Isfahan University of Technology, Department of Textile Engineering, Isfahan, Iran.

**Correspondence to: L. Moroni, University of Twente, Department of Tissue Regeneration, Enschede, The Netherlands.

E-mail addresses: elahe_mas@tx.iut.ac.ir (E. Masaeli), p.a.wieringa@utwente.nl (P.A. Wieringa),morshed@cc.iut.ac.ir (M. Morshed), mh_nasr@med.mui.ac.ir (M.H. Nasr-Esfahani), sadri@cc.iut.ac.ir (S. Sadri), c.a.vanblitterwsijk@utwente.nl (C.A. van Blitterswijk), 1.moroni@utwente.nl (L. Moroni). enhanced nerve repair has been reported following cell transplantation. ${ }^{1}$ In vitro and in vivo assessments have identified the use of bioengineered scaffolds seeded with SCs as a promising approach in synthetic nerve grafts to bridge nerve gaps. ${ }^{2,3}$ The success of SCs in nerve regeneration is related to the production of cell adhesion molecules and neurotrophic factors, which mediate neurite attachment and growth., ${ }^{4,5}$

Scaffolds for nerve regeneration require appropriate biocompatibility and biodegradability, good pliability for suture and mechanical integrity, and in vivo physiological loading during axon regeneration across large nerve defects. Scaffolds should also provide contact guidance for cell migration and axon outgrowth along the gap defect to support nerve functional regeneration. ${ }^{6}$

Recently, electrospun nanofibrous scaffolds served as suitable environments for cell attachment and proliferation thanks to similar physical dimensions and cues compared to natural extracellular matrix $(\mathrm{ECM}){ }^{7}$ Poly $[(R)-3$-hydroxybutyrate $](\mathrm{PHB})$ and poly $[(R)$ 3-hydroxybutyrate-co- $(R)-3$-hydroxyvalerate] (PHBV) are two 
extensively studied natural derived poly(hydroxyalkanoates) (PHAs) due to their good biocompatibility and mechanical properties. $^{8}$ In recent years, promising studies aimed at the engineering of tissues such as bone, ${ }^{9}$ cartilage, ${ }^{10}$ skin $^{11}$ and nerve $^{3}$ have used PHB or PHBV substrates as a scaffold.

Normally, cell affinity toward polymers is poor as a result of their low hydrophilicity and lack of surface cell recognition sites. ${ }^{12}$ Therefore, surface treatment of polymeric scaffolds is necessary to improve their bioactivity to achieve functional tissue regeneration. While various studies improved the hydrophilicity and surface properties of PHAs scaffolds using techniques such as composite electrospinning, ${ }^{13}$ plasma treatment, ${ }^{14,15}$ photografting ${ }^{16}$ and alkaline hydrolysis, ${ }^{15,17}$ very few studies have been reported in the literature on the surface functionalization of PHAs electrospun fibrous scaffolds with peptides for neural tissue engineering applications. ECM proteines have been so far the most used biomolecules, on the basis that cells in native tissues are surrounded by and attach to this network of fibril proteins. Meng et al. fabricated nanofibrous scaffolds using a blended solution of PHBV/collagen, which showed to accelerate adhesion and growth of NIH-3T3 cells. ${ }^{13}$ Alternatively, collagen can be immobilized on the surface of PHBV scaffolds, as reported by Tesema et al. and Baek et al., ${ }^{18,19}$ to improve their osteoblasts compatibility. Surface functionalization of PHBV-chitosan scaffolds grafted with hyaluronic acid (HA) has also been demonstrated by $\mathrm{Hu}$ et al., showing that antibacterial properties were maintained while protein adsorption was effectively reduced. ${ }^{20}$ Within the context of nerve repair, Armstrong et al. and Novikova et al. showed that coating of PHB nerve conduits with ECM molecules such as laminin and fibronectin enhanced SCs activity to release neurite promoting factors, ${ }^{3,21}$ highlighting the potential of adding ECM biomolecules to bioengineered nerve conduits in order to improve nerve regeneration. However, the complexity and source of ECM proteins can cause issues with consistency and control over cell response as well as final clinical translation. ${ }^{22}$ Synthetically produced peptides represent a viable alternative, as shown by Wang et al. ${ }^{23}$ with the introduction of RGD peptides on PHBV films; although not for a neural regeneration application, the viability of fibroblast-like NIH 3 T3 cells was shown to improve.

Building on our previous work developing fibrous PHB/PHBV electrospun scaffolds with optimal physical properties and fiber alignment for improved SC activity, we compare here for the first time the biological activity of electrospun PHB/PHBV fibrous scaffolds which have been functionalized with relevant peptides: GRGDS, and the two laminin derived neuromimetic peptide sequences YIGSR and p20. These biomolecules were chosen based on their biological functionalities as cues present in the basal ECM and known to be involved in cell-cell and cell-ECM communications. We also show the immobilization of collagen type I for further comparison, following our earlier observations that SC adhesion and proliferation was enhanced when collagen was blended into the PHB/PHBV fibers. ${ }^{24}$

\section{Methods}

\section{Materials}

PHB with $\mathrm{M}_{\mathrm{w}}$ of $437^{\prime} 000$, PHBV with $5 \%$ wt poly (3hydroxyvalerate) and $\mathrm{M}_{\mathrm{w}}$ of 150 '000, chloroform, $N, N$-dimethyl formamide (DMF), 2-(N-morpholino) ethanesulfonic acid (MES), sodium hydroxide $(\mathrm{NaOH}), N$-hydroxysulfosuccinimide sodium salt (sulfo-NHS) and 1-ethyl-3-(3-dimethylaminopropyl) carbodiimide hydrochloride (EDAC) were acquired from Sigma Aldrich (USA). Purchased reagents for cell culture were as follows: fetal bovine serum (FBS) from Hyclone (USA), Dulbecco Modified Eagle Medium (DMEM), phosphate buffered saline (PBS), penicillin/streptomycin and trypsin-EDTA from Gibco BRL (USA). Acid soluble collagen type I powder of bovine origin was a generous gift from Kensey Nash Corporation (USA). Peptides for biofunctionalization consisted in H-Gly-Arg-Gly-Asp-Ser-OH (GRGDS; $\mathrm{M}_{\mathrm{w}}$ : $490.47 \mathrm{~g} / \mathrm{m}$ ), H-Tyrlle-Gly-Ser-Arg-NH2 (YIGSR; $\mathrm{M}_{\mathrm{w}}: 594.67 \mathrm{~g} / \mathrm{m}$ ), and H-Arg-Asnlle-Ala-Glu-lle-lle-Lys-Asp-lle-OH (RNIAEIIKDI (p20; $\mathrm{M}_{\mathrm{w}}$ : $1184.40 \mathrm{~g} / \mathrm{m})$ ), and were purchased from Bachem (Switzerland).

\section{Electrospinning of aligned $\mathrm{PHB} / \mathrm{PHBV}$ nanofibers}

PHB/PHBV (1:1) solutions were prepared by dissolving the polymers in a chloroform (90)/DMF (10) solvent mixture at a concentration of $6 \%$ wt. Using a syringe pump (KDS 100, KD Scientific), the solution was fed at a rate of $1.5 \mathrm{ml} / \mathrm{min}$ through a $10 \mathrm{cc}$ syringe with a $23 \mathrm{G}$ needle placed $15 \mathrm{~cm}$ from a rotating mandrel collector with a speed of $5000 \mathrm{rpm}$. A high-voltage power supply was used to apply a voltage of $16 \mathrm{kV}$ DC to produce nanofibers. Temperature and humidity were monitored during the process and ranged between 24 and $26^{\circ} \mathrm{C}$ and $37 \%$ and $42 \%$, respectively.

\section{Covalent attachment of biomolecules on alkaline hydrolysed PHB/PHBV nanofibers}

For biofunctionalization, PHB/PHBV nanofibrous mats were firstly treated with $\mathrm{NaOH}(1 \mathrm{~N})$ for $80 \mathrm{~min}$ at room temperature, washed and dried at $37{ }^{\circ} \mathrm{C}$ overnight to obtain hydrolysed scaffolds. Afterwards, the hydrolysed scaffolds were washed in MES buffer solution (0.1 M, pH 5.0) for $30 \mathrm{~min}$ at room temperature to be subsequently activated with $5 \mathrm{mg} / \mathrm{ml}$ EDAC and $2.5 \mathrm{mg} / \mathrm{ml}$ sulfo-NHS in MES buffer solution for $90 \mathrm{~min}$ at room temperature. Biofunctionalization with collagen $(5 \mathrm{mg} / \mathrm{ml}$ PBS) and peptides $(0.2 \mathrm{mg} / \mathrm{ml} \mathrm{PBS})$ solutions was performed for 24 hours at room temperature. Scaffolds were further rinsed with PBS and dried at $37^{\circ} \mathrm{C}$ overnight (Figure 1).

\section{Characterization of nanofibrous scaffolds}

\section{Scanning electron microscopy (SEM)}

The morphology of electrospun fibers was observed using SEM (XL 30 ESEM-FEG, Philips). Fiber diameters were calculated from SEM micrographs by measuring 100 fibers using Manual Microstructure Distance Measurement software (NahaminPardazan Asia Co., Iran).

\section{Monitoring of biofunctionalization method on scaffolds}

Attenuated total reflectance Fourier transform infrared spectroscopy (ATR-FTIR) of collagen immobilized and bulk PHB/PHBV nanofibrous scaffolds were performed over a range of $400-4000 \mathrm{~cm}^{-1}$ at a resolution of $2 \mathrm{~cm}^{-1}$ using a Nicolet spectrometer system.

The XPS spectra of GRGDS immobilized and bulk PHB/ PHBV nanofibrous scaffolds were also obtained on VGEscalab 2201-XL Base System (Thermo VG Scientific, UK) with a take- 


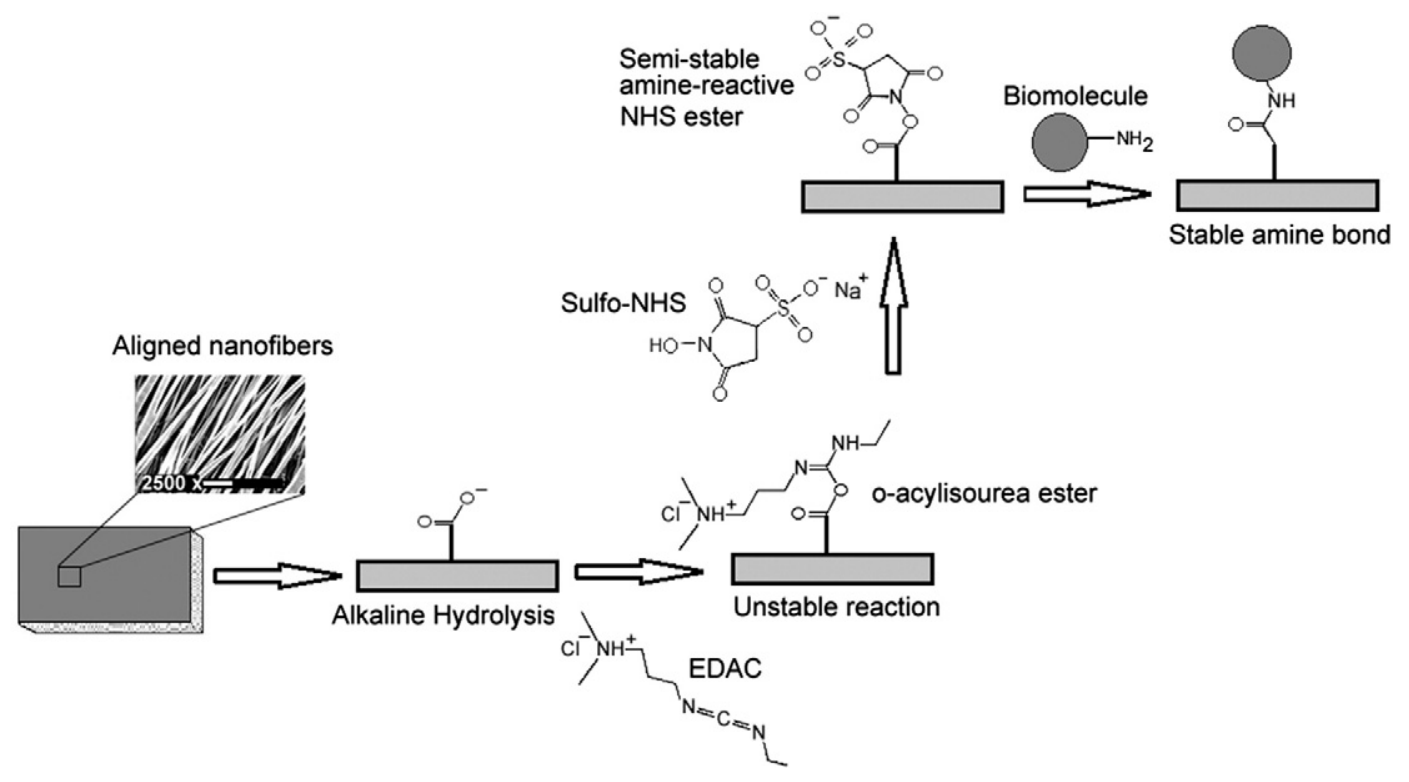

Figure 1. Schematic representation of covalent attachment of biomolecules on the surface of PHB/PHBV nanofibrous scaffolds. Electrospun fibers are first subjected to alkaline hydrolysis, after which fibers were treated with a solution of EDAC and NHS. Fibers were then functionalized with collagen or peptide sequences, where the amine-reactive NHS groups on the fiber surface covalently bind biomolecules in solution.

off angle of $90^{\circ}$. Briefly, survey scan spectra were taken and the ratio of $\mathrm{C} 1 \mathrm{~s}, \mathrm{~N} 1 \mathrm{~s}$ and $\mathrm{O} 1 \mathrm{~s}$ of samples were indicated.

\section{Surface wettability measurements}

Water contact angle $(\theta)$ of each scaffold was determined on a contact angle goniometer (Dataphysics OCA-20) by at least five independent measurements, while deionized water was used as a probe liquid.

\section{Pretreatment of scaffolds before cell culture}

Electrospun discs with a diameter of $15 \mathrm{~mm}$ and thickness of about $300 \mu \mathrm{m}$ were soaked in $70 \%$ ethanol for 2 hours, washed twice with PBS, transferred to a 24 well non-treated plate and incubated overnight in basic cell culture medium. Rubber Orings (Eriks BV, The Netherlands) were used to secure the scaffolds in place and prevent them from floating.

\section{Quantification of protein immobilization}

The amount of surface protein was evaluated using a BCA protein assay (Thermo Scientific). Scaffolds were washed for 24 hours in PBS at $4{ }^{\circ} \mathrm{C}$ followed by another 1 hour wash in $1 \% \mathrm{w} / \mathrm{v}$ SDS in Tris buffer at $\mathrm{pH} 8.5$ (Sigma Aldrich, USA) to hydrolyze NHS groups and remove any residual absorbed proteins. Afterwards, scaffolds were rinsed twice in $1 \% \mathrm{SDS} /$ Tris solution, followed by a 2 times wash in PBS. Finally, scaffolds were immersed in the BCA solution (with appropriate dilution to simulate the addition of a protein solution) and mixed at $1000 \mathrm{rpm}$ for $30 \mathrm{~min}$ at $37^{\circ} \mathrm{C}$ and $60^{\circ} \mathrm{C}$ for collagen and peptide immobilized scaffolds, respectively. To resolve protein concentration, BCA standard curves of each protein in solution were generated using a dilution series. All scaffold conditions were prepared in duplicate and measured in triplicate. Data analysis was performed using R and Deducer Package (Ian Fellows).

\section{Cell culture}

Schwann cell line RT4-D6P2T (ATCC, USA) was cultured in high glucose DMEM, and supplemented with $10 \%$ FBS and 1\% penicillin/streptomycin. Cells were seeded at a density of about 50 '000 cells/well on sterilized scaffold in $50 \mu \mathrm{l}$ basic medium and incubated for $30 \mathrm{~min}$ to allow cell attachment and topped up to $1 \mathrm{ml}$ with culture medium.

\section{Cell-scaffold studies}

\section{Cell morphology study}

For morphology investigations, the cells were fixed in $4 \%$ formalin for $30 \mathrm{~min}$ and dehydrated in a series of increasing ethanol concentrations $(70 \%, 80 \%, 90 \%, 96 \%$, and $100 \%)$, $30 \mathrm{~min}$ in each concentration, before being dried using a critical point dryer (Balzers CPD-030). Finally, the samples were sputter-coated with gold (Cressington) for SEM observation.

\section{Immunofluorescent staining}

Cells were washed with PBS, fixed with $4 \%(\mathrm{v} / \mathrm{v})$ paraformaldehyde (Sigma) in PBS for $30 \mathrm{~min}$ and washed again with PBS. Afterwards, blocking was performed with $10 \%$ $(w t / v)$ BSA in PBS for 1 hour. Primary antibodies against p75 low affinity NGF receptor (p75LNGFR, 1:500, Abcam; ab6172) were applied in dilute buffer consisting of $10 \%(\mathrm{wt} / \mathrm{v}) \mathrm{BSA}$ in PBS overnight at $4{ }^{\circ} \mathrm{C}$. Cells were then washed and the secondary antibody, goat anti-mouse IgG conjugated-fluorescein isothiocyanate (FITC, 1:50), was applied for $45 \mathrm{~min}$ at $37^{\circ} \mathrm{C}$. Cells were counterstained with DAPI for $10 \mathrm{~min}$ and observed under fluorescence microscope. For negative controls, the primary antibody was excluded.

To quantify the p 75 positive staining, we used the Sauvola binarization method. Firstly, we converted original true color immunostaining images ( $0: 255$ values) of cultured SCs on each 
scaffold to binary images (0:1 values). Then, we applied digital image processing algorithms to these double precision $(\mathrm{n}=10)$. After creation of a disk morphological structuring element with the specified radius and applying the Sauvola binarization method, the area of white zones in each binary image was measured as a quantitative value of $\mathrm{p} 75$ positive zones.

\section{Cell metabolism study (Presto blue assay)}

Metabolic activity of cells were monitored after 1, 3, 7 and 14 days $(\mathrm{n}=3)$ by Presto blue assay according to the manufacturer's protocol. Briefly, cells were incubated with medium containing 10\% (v/v) Presto blue solution (Biosource, USA). After the designated time periods, aliquots were pipetted into a 96-well plate and the absorbance of the content of each well was measured at $590 \mathrm{~nm}$ using a multilabel plate reader (Victor3, Perkin Elmer, USA).

Proteinase-K digestion and cell proliferation study (DNA assay)

After 1 and 14 days of cell culture, scaffolds were washed in PBS and frozen at $-80^{\circ} \mathrm{C}$ until further processing. Subsequently, they were digested at $56^{\circ} \mathrm{C}(>16$ hours) in a Tris-EDTA buffered solution containing $1 \mathrm{mg} / \mathrm{ml}$ proteinase-K, $18.5 \mu \mathrm{g} / \mathrm{ml}$ pepstatin A, and $1 \mu \mathrm{g} / \mathrm{ml}$ iodoacetamide (Sigma-Aldrich). DNA quantification assay was performed with a CyQuant dye kit according to the manufacturer description (Molecular Probes, Eugene, USA), using above spectrofluorometer, at an excitation wavelength of $480 \mathrm{~nm}$ and an emission wavelength of $520 \mathrm{~nm}$.

\section{ELISA assay of NGF secretion (NGF assay)}

To quantify the concentration of nerve growth factor (NGF) in cell cultured supernatant, commercially available ELISA kits were used according to the manufacturer's instruction (Promega). The plates were read at $450 \mathrm{~nm}$ and analyzed using a Lightcycler II (Roche Diagnostics GmbH, Germany). Secretions of NGF were measured at 3, 6, 12 and 14 days of culture $(n=3)$.

\section{$R N A$ extraction and quantitative real-time $R T-P C R$}

For time reverse transcription polymerase chain reaction (real-time PCR) analysis, total RNA was isolated using a combination of TRIzol ${ }^{\circledR}$ with a NucleoSpin ${ }^{\circledR}$ RNA II isolation kit (Bioké). Briefly, after 7 days of cell culture, scaffolds $(n=3)$ were washed with PBS once and $1 \mathrm{ml}$ of TRIzol (Invitrogen) was added to the samples. The samples were then stored at $80{ }^{\circ} \mathrm{C}$ for RNA isolation. After chloroform addition and phase separation by centrifugation, the aqueous phase containing the RNA was collected, mixed with an equal volume of $75 \%$ ethanol and loaded onto an RNA binding column. RNA was collected in RNase-free water. 750 nanograms of RNA was used for first strand cDNA synthesis using iScript (Bio-Rad) and $1 \mu \mathrm{l}$ of undiluted cDNA was used for subsequent analysis. RT-PCR was performed on an iQ5 real time PCR machine (Bio-Rad) using SYBR Green supermix (Bio-Rad). Expression of neural marker genes (Table S2) was normalized to $\beta$-actin levels and fold inductions were calculated using the comparative $\Delta \mathrm{CT}$ method.

\section{Statistical analysis}

All data presented are expressed as mean \pm standard deviation (SD). Statistical analysis was carried out using one-way analysis of variance (ANOVA) followed by a Tukey's post hoc test. A value of $P<0.05$ was considered statistically significant.

\section{Results}

Characterization of fibrous scaffolds

Electrospinning of $\mathrm{PHB}(50) / \mathrm{PHBV}(50)$ solutions resulted in a scaffold composed of uniform, uniaxially oriented nanofibers of an average diameter of $925 \pm 156 \mathrm{~nm}$ (Figure 2). More specifically, the distribution of the fibers had two peaks with average diameters of $577.5 \pm 80.4 \mathrm{~nm}$ and $1074 \pm 123.3 \mathrm{~nm}$, respectively. Our previous studies showed that approximately $60 \%$ of the fibers had a diameter of $1074 \mathrm{~nm}$, thus confirming a rather narrow fiber distribution. ${ }^{24}$ Apart from common peaks of the PHAs backbone, ATR-FTIR spectra of both scaffolds exhibited additional absorption peaks for collagen immobilized PHB/PHBV fibers at $1640 \mathrm{~cm}^{-1}$ associated with the $\mathrm{C}=\mathrm{O}$ stretching of amide $\mathrm{I}$ and at $1560 \mathrm{~cm}^{-1}$ associated with the N-H bending of amide II (Figure S1). These peaks confirmed the successful immobilization of the collagen on the surface of the scaffolds.

XPS analysis of unmodified and GRGDS immobilized fibers showed an additional N1s peak in the survey spectra of GRGDS modified samples at $401.92 \mathrm{eV}$ (Figure S2), which clearly suggests that the GRGDS is chemically conjugated on the surface of the fibers. Table S1 also lists the intensities (i.e., the measured peaks divided by the corresponding sensitivity factors and normalized to $100 \%$ total intensity) of the elements on the two different surfaces.

BCA analysis revealed that there is a greater amount of collagen bound compared to the peptide sequences, in accordance with the relatively larger size of whole collagen fibrils and their initial concentration in solution (Figure S3). Immobilized peptide concentration of GRGDS, YIGSR and p20 decrease by weight was in agreement with the relative reduction of molar concentration of the initial peptide solutions. A similar comparison with the collagen solution was not possible because of the unknown molecular weight.

Wettability measurements showed that the water contact angle values were $107.4 \pm 5.0^{\circ}$ for aligned PHB/PHBV nanofibers and reached zero after alkaline hydrolysis, resulting in $100 \%$ wettability by the water droplet.

\section{Morphological studies of SCs}

After 1 day from seeding, cells oriented themselves along the direction of fiber alignment and clustered around the aligned fibers in a longitudinal fashion (Figure 2). Cells seemed to spread more on laminin derived peptide functionalized scaffolds than on other meshes. Immunocytochemistry indicated that cultured SCs on biofunctionalized scaffolds were positive for p75LNGFR, thus confirming normal cell functionality (Figure 3). Figure 4 shows outputs of digital image processing analysis to quantify amounts of p75 positive zones in each immunostaining image. Biofunctionalized scaffolds supported a stronger expression of p75LNGFR, with collagen, GRGDS, and YIGSR functionalized fibers significantly better than p20, thus suggesting enhanced SCs differentiation compared to non-functionalized and alkaline hydrolyzed scaffolds.

\section{Metabolic activity and proliferation of SCs on fibrous scaffolds}

Metabolic activity of cells on all scaffolds increased during the 14-day period (Figure 5, $A$ and $B$ ). While in the first 7 days of cell culture, SCs metabolic activity increased just on GRGDS 

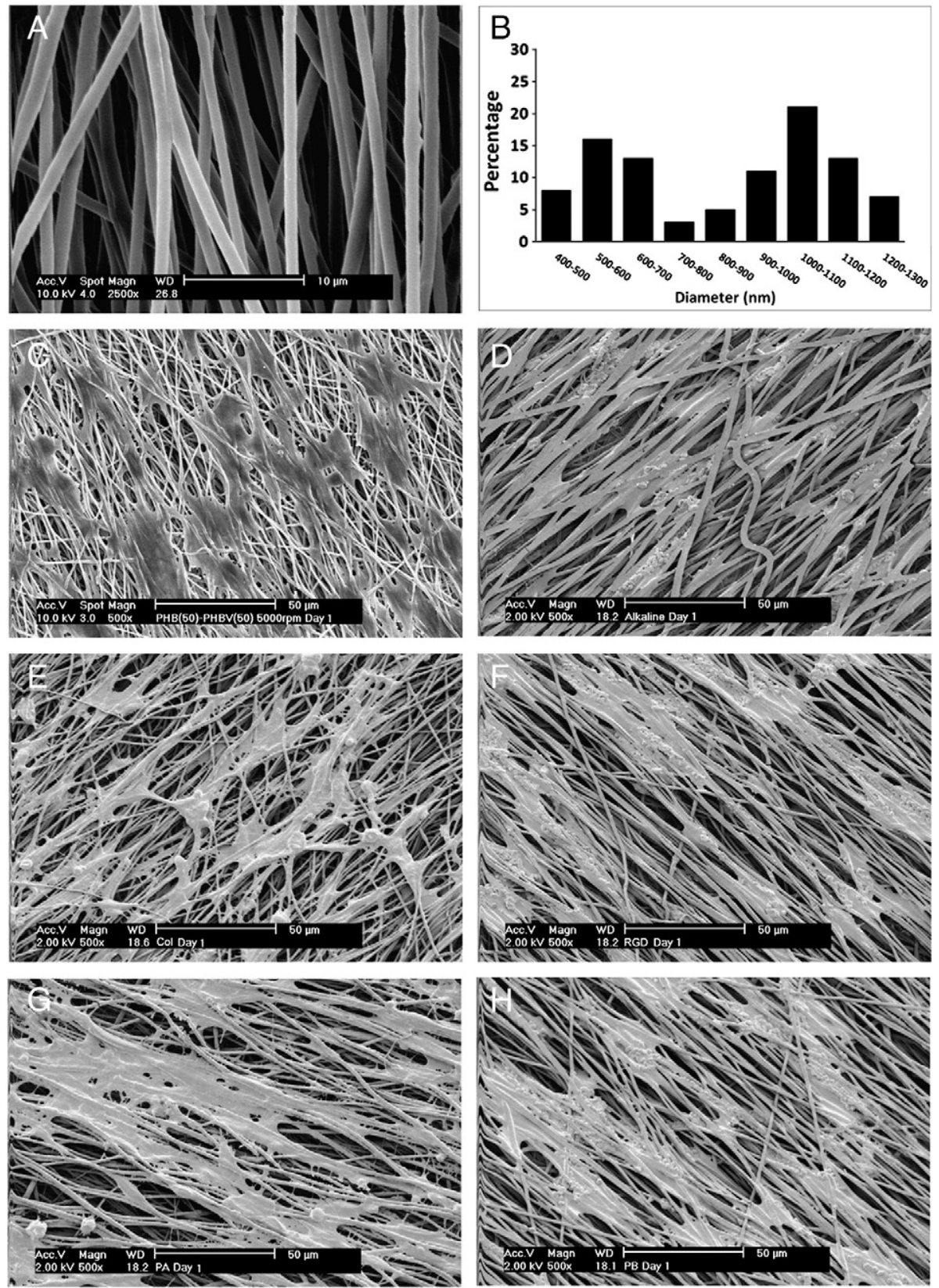

Figure 2. SEM micrograph (A) and fiber diameter distribution (B) of PHB/PHBV nanofibres. SEM images of SCs on (C) untreated, (D) alkaline hydrolysed, (E) collagen, (F) GRGDS, (G) p20 and (H) YIGSR immobilized scaffolds 1 day after cell culture. Scales bars: (A) $10 \mu \mathrm{m} ;(\mathbf{C}-\mathbf{H}) 50 \mu \mathrm{m}$.

immobilized fibers, after 2 weeks of culture such an increase was significant on all functionalized nanofibers compared to those observed on the unmodified and alkaline hydrolysed samples $(P<0.05)$. The DNA quantification results also showed increased proliferation of SCs on different scaffolds from day 1 to day 14 (Figure 5, $C$ and $D$ ). On day 14, SCs proliferation on all functionalized nanofibers increased significantly compared to unmodified and alkaline hydrolysed scaffolds, while on day 1 SCs proliferation was found to be higher $(P<0.05)$ just on GRGDS immobilized nanofibrous scaffolds, in agreement with metabolic activity results. These findings indicated a better effect of the applied biomolecules on SCs metabolic activity, likely resulting in higher proliferation rate compared to unmodified or alkaline hydrolysed scaffolds.

Gene expressions and NGF released from cultured SCs on nanofibrous scaffolds

The gene expression of different SCs markers was analyzed using quantitative RT-PCR and obtained results are presented in Figure 6. No statistically significant difference was observed on SCs cultured on unmodified and biofunctionalized scaffolds for PMP22. The presence of GRGDS and both laminin derived peptides in the scaffolds tended to significantly upregulate 


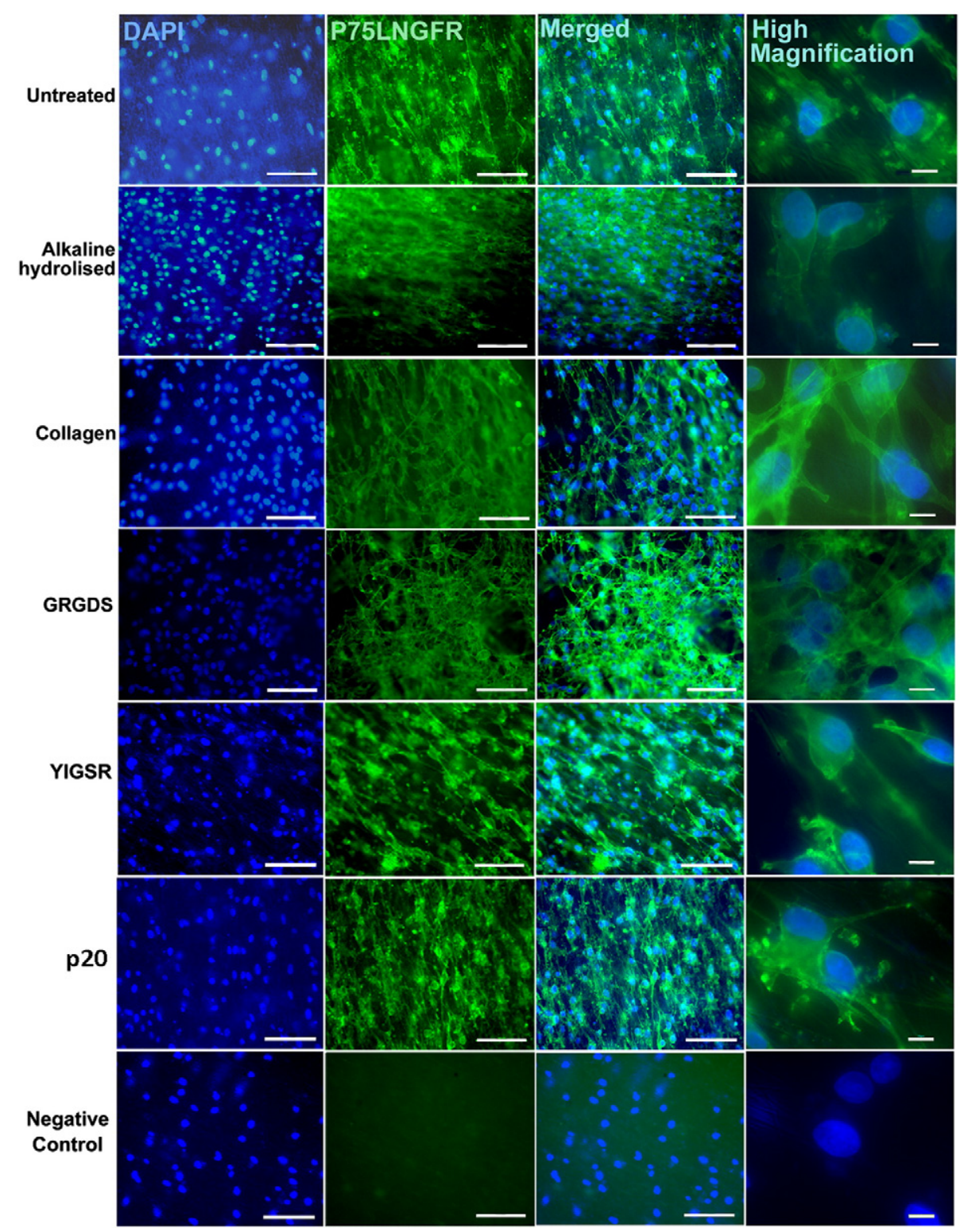

Figure 3. Immunostaining identification of SCs by p75LNGFR and counterstained by DAPI, after 7 days of culture on electrospun scaffolds which were untreated, hydrolyzed, or functionalized with respective biomolecules. Tissue culture plastic well plate served as a negative control. Cell adhesion and p75LNGFR expression is shown for all scaffolds, with little or no expression observed for the negative control condition. Scale bars show $100 \mu \mathrm{m}$ and $10 \mu \mathrm{m}$ for low and high magnifications, respectively.
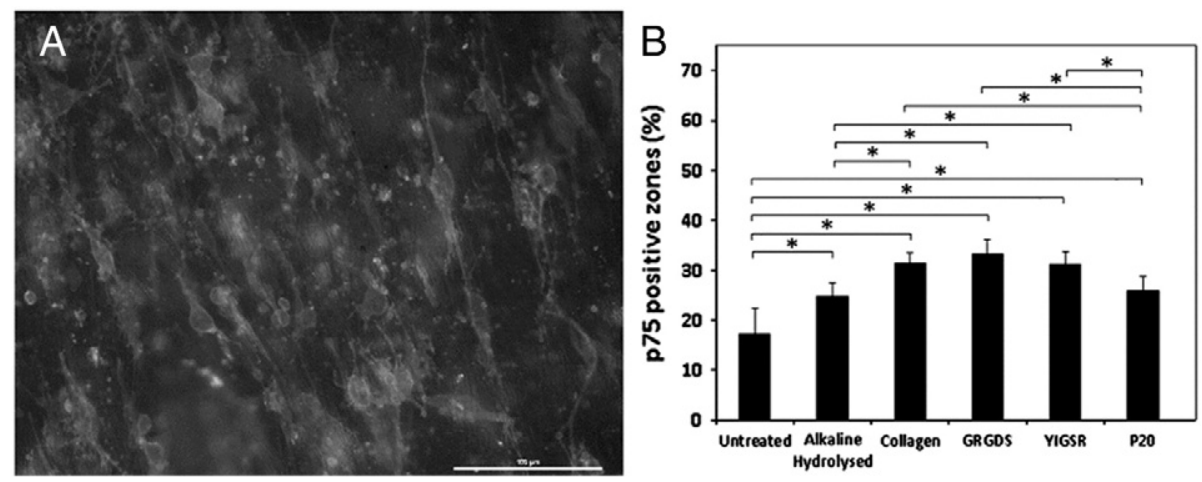

Figure 4. (A) Original immunostaining image of SCs on untreated PHB(50)/PHBV(50) nanofibrous scaffold, (B) average percentage of p75LNGFR positive zones on different scaffolds calculated by image processing algorithms. Asterisks represent statistically significant difference at $P<0.05$. 

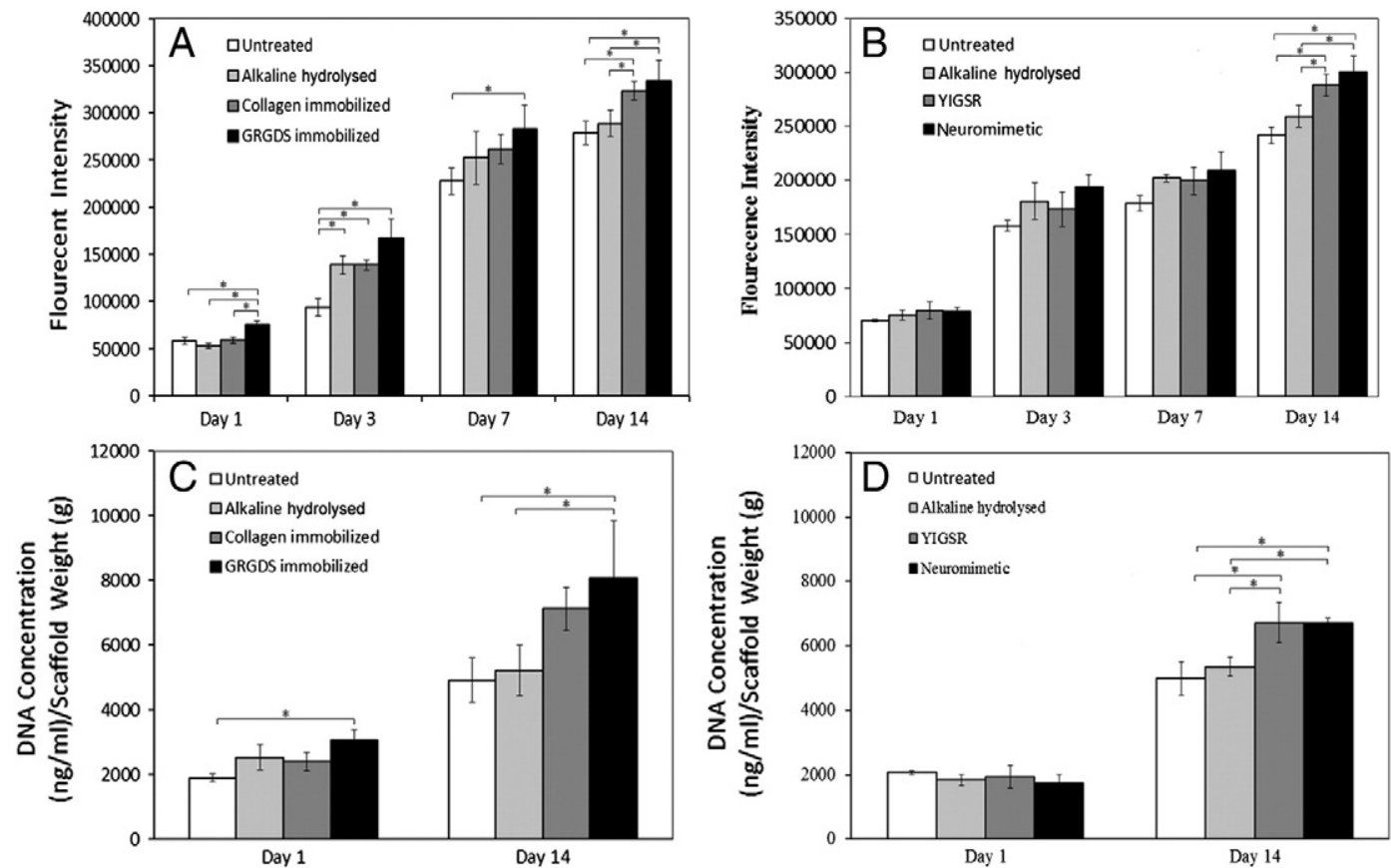

Figure 5. Metabolic activity (A, B) and proliferation (C, D) of SCs on collagen and RGD functionalized scaffolds (A, C) and YIGSR and neuromimetic functionalized scaffolds (B, D). Peptide-functionalized scaffolds were shown to have consistently increased metabolic activity and proliferation compared to collagen-functionalized and non-functionalized scaffolds. Asterisks represent statistically significant difference at $P<0.05$.
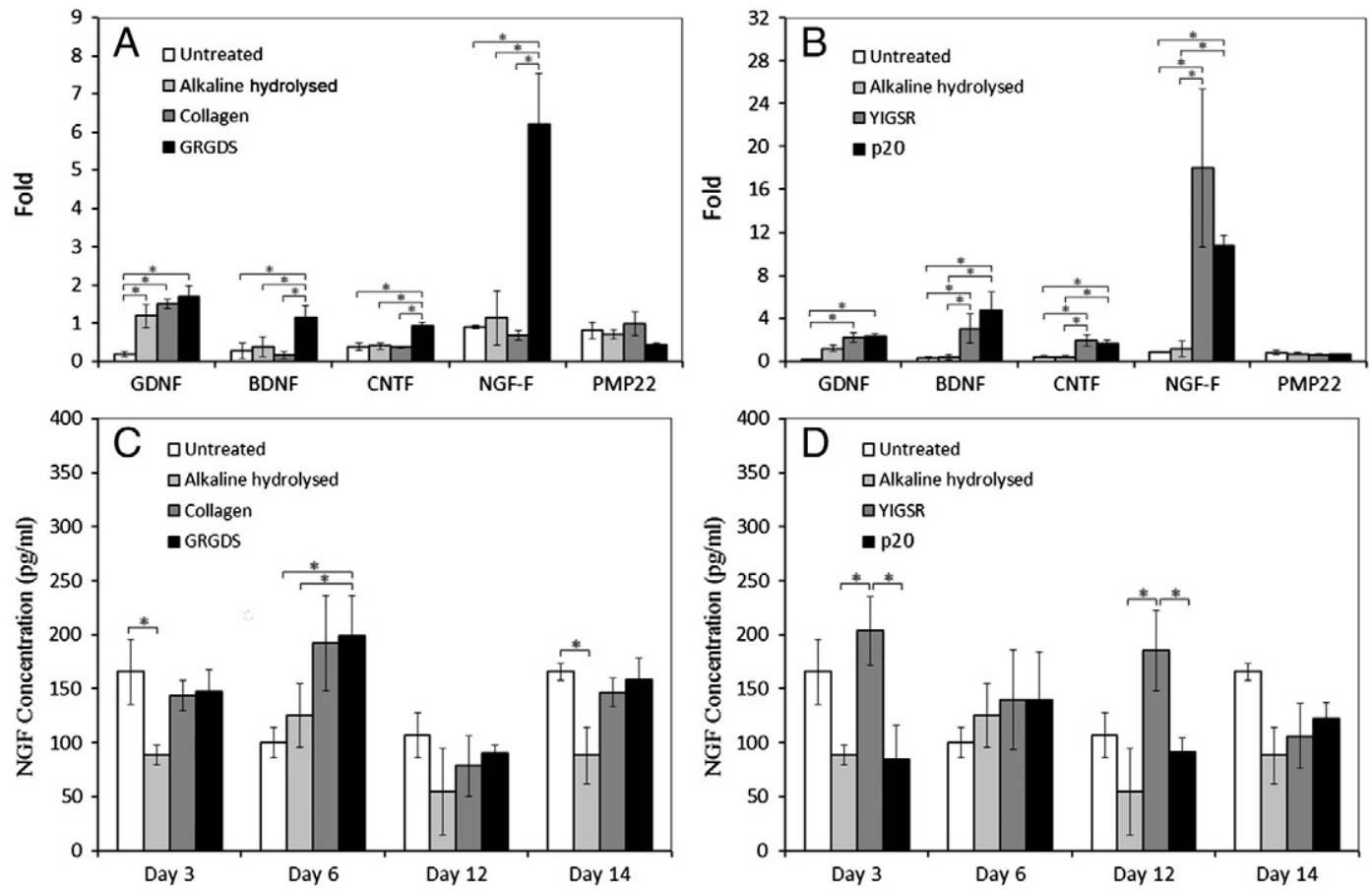

Figure 6. Real-time PCR of neurotrophin gene expression in SCs grown on scaffolds functionalized with GRGDS or collagen, compared to untreated or hydrolysed scaffolds at day 7 (A). GRGDS functionalization supported an increased expression of GDNF, BDNF, CNTF and NGF over the other scaffolds. Looking at NGF secretion over a 2 week period a major difference on day 6 between biofunctionalized and non-functionalized scaffolds was measured (C), with no observable differences between collagen and GRGDS. Neurotrophin gene expression on laminin peptide functionalized scaffolds was also shown to similarly upregulate GDNF, BDNF, CNTF and NGF compared to non-functionalized scaffolds (B). The gene upregulation of laminin peptide functionalized scaffolds was also significantly higher than GRGDS and collagen functionalized scaffolds. Subsequent NGF secretion showed marked differences for only YIGSRfunctionalized scaffolds on day 3 and day 12. The fold induction of gene expression was normalized with respect to an endogenous reference of $\beta$-actin (housekeeping gene). Asterisks represent statistically significant difference at $P<0.05$. 
GDNF, BDNF, CNTF and NGF-F expression in comparison to untreated scaffolds indicating that applied peptides might have accelerated SCs differentiation $(P<0.05)$.

Furthermore, no significant difference between GDNF and PMP22 expressions of SCs on GRGDS, YIGSR and p20 groups was observed, while BDNF and CNTF expressions were significantly higher on both laminin derived peptide modified scaffolds compared to GRGDS $(P<0.05)$. Also the difference between BDNF and CNTF expression of GRGDS immobilized sample was not significant. Significantly higher expression of NGF-F on YIGSR immobilized scaffold was also found than those of p20 and GRGDS ones $(P<0.05)$.

Figure 6, $C$ and $D$ show concentrations of NGF released from cultured SCs on different scaffolds. Biofunctionalization with collagen and GRGDS did not have any positive effect on NGF secretion of the cultured SCs, except at day 6 (Figure 6,C). After 3 and 12 days of cell culture, NGF concentration of YIGSR immobilized scaffolds were significantly higher than that of untreated nanofibers $(P<0.05)$ (Figure $6, D)$. In general, NGF assay results of SCs on YIGSR modified nanofibers confirmed NGF-F expression obtained by real-time PCR.

\section{Discussion}

\section{Characterization of unmodified and modified nanofibrous scaffolds}

Electrospinning is an established method for fabricating nanofibrous scaffolds to mimic ECM-like properties such as nanoscale dimensions, high porosity, and large surface area for tissue engineering applications. This method produces nonwoven meshes containing fibers ranging in diameter from tens of microns to tens of nanometers with different orientation, which makes electrospinning more appealing than other submicron fiber fabrication. ${ }^{7,25}$ In this study, we used a high speed mandrel to collect uniaxially aligned $\mathrm{PHB} / \mathrm{PHBV}$ nanofibers. SEM results showed homogenous and continuous structure of electrospun fibers with a high degree of orientation (Figure 2, A). Similarly, Matthews et al. reported that electrospun collagen fibers maintained random orientation at rotational speeds less than $500 \mathrm{rpm}$ and significant fiber alignment when the speed of the mandrel was increased to $4500 \mathrm{rpm}^{26}$

Surface properties of scaffolds are also extremely important, as they affect the biological interactions of the substrate with cells and tailor the responses across the interface with the host tissue. ${ }^{27}$ Normally, the relatively poor hydrophilicity of PHB and PHBV affects their biocompatibility for application in tissue engineering. To improve the hydrophilicity and surface bioactivity of PHB/PHBV scaffolds, different types of physicochemical and post-processing surface modification techniques such as hydrolysis with lipases and $\mathrm{NaOH},{ }^{28}$ low pressure plasma treatment $^{14}$ and ion implantation, ${ }^{29}$ have been attempted. Immobilization of specific proteins or peptide sequences on the scaffold surface that mimic natural components is a promising method to obtain surface properties especially tailored for tissue engineering. When proteins are considered for functionalizing an artificial substrate, natural choices are ECM molecules such as laminin, fibronectin, and collagen, which activate integrin receptors. ${ }^{12}$ However, these ECM molecules often present cells with multiple types of integrin binding sites and other cell signaling motifs and, therefore, limit the degree of specificity over the cell response that can be elicited. ${ }^{22}$ An alternative is biofunctionalizing a surface with peptide sequences based on moieties found in ECM proteins, employing peptides that bind specific membrane-bound receptors to promote cellular adhesion, differentiation, and other intracellular signaling cascades via defined cell/substrate interactions. ${ }^{5}$

In this study, we used collagen I and the integrin binding GRGDS, YIGSR and p20 peptides to functionalize the surface of aligned PHB/PHBV nanofibers. Covalent modification was performed by presenting reactive carboxyl groups $(-\mathrm{COOH})$ through alkaline hydrolysis. ATR-FTIR showed that after immobilization with collagen the extra absorption peaks of amide I and amide II appeared in the spectra of functionalized nanofibrous scaffolds (Figure S1). Similar results have been reported by Mattanaave et al. during immobilization of collagen onto surface of PCL nanofibers. ${ }^{30}$ Because of a low concentration of peptides used for functionalization, we used XPS as a more accurate detection method to determine the presence of GRGDS peptide on the surface of PHB/PHBV nanofibrous scaffolds as an evidence for effective functionalization.

From Figure S2, it can be seen that unmodified PHB/PHBV fibers fail to show any N1s peaks, while we can clearly attribute the N1s peak to the chemically immobilized GRGDS on the surface of the nanofibers, thus confirming successful peptide biofunctionalization. Similar N1s peak around $400 \mathrm{eV}$ was also observed by Wang et al. after immobilization of RGD peptides on the surface of PHBV films. ${ }^{23}$ Furthermore, immunostaining analysis against anti-collagen I showed that functionalized coating was stable after 22 months from biofunctionalization in a sealed container at room temperature (data not shown), thus suggesting that our procedure was stable in time.

\section{In vitro studies of SCs with unmodified and modified nanofibrous scaffolds}

As SCs play an important role in axonal regeneration and function recovery of neurons, they should effectively attach, spread, and differentiate on scaffolds. SEM images of SCs obtained on day 1 of cell culture on scaffolds showed that SCs cultured on the aligned webs oriented along the fibers; thus, the aligned fibrous scaffolds could exhibit SCs columns, also known as band of Büngner (Figure 2, $C$ to $H$ ). It has well been documented that fiber orientation influences cell adhesion and growth, while it also modulates elongated cellular patterns that match cell morphology found in native tissues. ${ }^{6,31,32}$ For PNS and spinal cord, previous studies demonstrated that aligned structures are capable of guiding neurite extension through a lesion site for axonal regeneration within the nerve. ${ }^{33,34}$ This finding is confirmed by similar results obtained by other researchers who reported that oriented arrangement of SCs on aligned electrospun fibrous mats might positively influence axonal regeneration. 6,31,35,36 Immunostaining analysis against p75LNGFR showed that SCs can adhere, migrate, and form elongated cellular processes on the surface of all scaffolds. Although it has been previously shown that neat PHB and PHBV scaffolds are non-toxic to SCs, ${ }^{37}$ the current study revealed a higher degree of spreading and a more intense p75LNGFR staining 
when PHB/PHBV nanofibers were functionalized with biomolecules (Figure 4). In this way, the positive response of the p75LNGFR observed in biofunctionalized scaffolds indicate improved reactivity that may further stimulate in vivo regeneration.

Furthermore, we have also shown that biofunctionalization of PHB/PHBV scaffolds increased metabolic activity and proliferation of SCs compared to unmodified scaffold (Figure 5). Previous studies proved that presence of RGD peptides on the surface of scaffolds can enhance proliferation of different cell types such as fibroblasts and SCs. ${ }^{23,36,38}$ In addition, it is well known that laminin contains bioactive neurite binding sites for neural cell attachment and differentiation, which enhance neurite extensions. ${ }^{39}$ From our results, the presence of biological cues enhanced SCs proliferation and metabolic activity compared to other groups (Figure 5). Thus, it appears that these peptides activated signaling pathways with an influence on cell cycle.

The improved SCs activity on peptide-modified scaffolds could be first the result of more hydrophilicity, which increases serum proteins adsorption. Secondly and most important, the presence of biomolecules on the surface of fibers might have allowed SCs to preferentially attach to the proteins of their native environment providing a surface bioactive scaffold. Previous studies showed that cell activity is extremely sensitive to surface chemical groups of scaffolds and varies with individual functional groups more significantly than with general surface properties like hydrophilicity. ${ }^{40}$ Wang et al. believed that protonation in the culture medium helps the adhesion of cells that carry negative charges on the membrane surface. N-containing groups, which resulted from peptide introduction to the surface of scaffolds, may be positively charged at physiological $\mathrm{pH}$ and caused protonation of cell culture medium. ${ }^{23}$ Ren et al. also showed that amino groups $\left(\mathrm{NH}_{2}\right)$ are very effective on nerve stem cell proliferation and migration. ${ }^{41}$ Hence, it may be concluded that the presence of amino groups on the surface of biofunctionalized scaffolds may account for improved SCs.

Another crucial issue regarding the application of biofunctionalized $\mathrm{PHB} / \mathrm{PHBV}$ nanofibrous scaffolds in neural tissue engineering is whether the presence of biomolecules altered SCs phenotype. After cultivation for 7 days, the expressions of neural genes associated to differentiation were detected. We also considered the upregulated gene expression of GDNF, BDNF, NGF, and CNTF, four well characterized neurotrophins known to stimulate growth of different types of neurons. These neurotrophic factors, therefore, may promote neurite sprouting from the transplantation site when translated into an in vivo model. ${ }^{42}$ PMP22, as the primary component of myelin protein, is known to be involved in formation and controlling myelin thickness and stability. ${ }^{43}$ In the present study, the comparison of the untreated and biofunctionalized scaffolds obviously indicated that SCs gene expressions in the unmodified group were down-regulated (Figure 6, $A$ and $B$ ), which agrees well with Feng et al. findings for avidin treated scaffolds compared to untreated ones. ${ }^{44}$ Previously, Ren et al. have also reported that, compared to $-\mathrm{COOH}$ surfaces, $-\mathrm{NH}_{2}$ seemed to promote neuronal stem cell differentiation. ${ }^{41}$ PMP22 was not altered by the presence of biologically active motifs. Chew et al. reported similar results indicating that aligned electrospun PCL scaffolds seeded with SCs did not change PMP22 expression. ${ }^{45}$ Further in vivo investigations are required to determine the effect of scaffold alignment and laminin motifs introduction on myelination since the result of the PMP22 gene expression was not conclusive in vitro.

The significant up-regulation of these neural genes indicates differentiation and maturation of SCs, which could benefit axonal regeneration and provide a more favorable microenvironment for peripheral nerve. Previous studies demonstrated that complementing exogenous neurotrophin or up-regulated neurotrophic gene expression can promote axonal regeneration. ${ }^{44,46}$ There is considerable evidence indicating that various neurotrophins such as NGF, BDNF, CNTF and GDNF, play an important role in nerve regeneration both in vitro and in vivo. ${ }^{47}$ Cai et al. showed that the neurotrophins released from SCs may enhance the regeneration of not only neural tissues, but also nonneural tissues, such as ligament, bone and periodontal membrane. ${ }^{48}$ Additionally, the up-regulation of SCs gene expression was significantly higher when fibers were functionalized with GRGDS compared to collagen type I and laminin derived peptides compared to all the other scaffolds.

To further analyze cell differentiation, we also investigated NGF secretion of cultured SCs. NGF has been widely explored among neurotrophic factors and shown to play a prominent role in experimental diabetic neuropathy. ${ }^{49}$ ELISA assay results showed a significant increase in NGF released by SCs cultured on YIGSR immobilized scaffolds on days 3 and 12 compared to p20 and alkaline hydrolysed scaffolds (Figure 6,D). Neither did GRGDS nor collagen containing scaffolds show any greater NGF secretion of SCs compared to untreated scaffolds except day 6 (Figure $6, C$ ). This might be explained by an early state of SCs differentiation triggered by the presence of the biomolecules, which results in upregulation of neural genes without a correspondent increase in NGF secretion. As exogenous NGF is rapidly disintegrated, ${ }^{50}$ we could also hypothesize that degradation of NGF during culturing times may reduce its secretion. Further studies should aim at evaluating protein secretion after a longer culturing period.

On the basis of the data obtained, we believe that the use of peptide functionalized $\mathrm{PHB} / \mathrm{PHBV}$ fibrous substrates enhances the response of SCs in vitro. Designed scaffolds not only enhanced SCs metabolic activity and proliferation but also maintained neural gene expression, which in the case of laminin derived peptides was also correlated to increased neurotrophic factors secretion. Therefore, laminin derived functionalized nanofibrous scaffolds can be pivotal in functional peripheral nerve regeneration.

\section{Appendix A. Supplementary data}

Supplementary data to this article can be found online at http://dx.doi.org/10.1016/j.nano.2014.04.008.

\section{References}

1. Dezawa M, Adachi-Usami E. Role of Schwann cells in retinal ganglion cell axon regeneration. Progress in retinal and eye, research; 2000.

2. Yu W, Zhao W, Zhu C, Zhang X, Ye D, Zhang W, et al. Sciatic nerve regeneration in rats by a promising electrospun collagen/poly( $\varepsilon$-caprolactone) 
nerve conduit with tailored degradation rate. BMC Neurosci 2011;12(1):68 [BioMed Central Ltd.].

3. Novikova LN, Pettersson J, Brohlin M, Wiberg M, Novikov LN. Biodegradable poly-b-hydroxybutyrate scaffold seeded with Schwann cells to promote spinal cord repair. Biomaterials 2008;29:1198-206.

4. Friedman HCH, Jelsma TN, Bray GM, Aguayo AJ. A distinct pattern of trophic factor expression in myelin-deficient nerves of trembler mice: implications for trophic support by Schwann cells. J Neurosci 1996;16 (17):5344-50.

5. Mey J, Brook G, Hodde D, Kriebel A. Electrospun fibers as substrates for peripheral nerve regeneration. In: Jayakumar R, Nair S, editors. Biomedical Applications of Polymeric Nanofibers SE - 122. Berlin Heidelberg: Springer; 2012. p. 131-70.

6. Cooper A, Bhattarai N, Zhang M. Fabrication and cellular compatibility of aligned chitosan-PCL fibers for nerve tissue regeneration. Carbohydr Polym 2011;85(1):149-56 [Elsevier Ltd.].

7. Masaeli E, Morshed M, Rasekhian P, Karbasi S, Karbalaie K, Karamali F, et al. Does the tissue engineering architecture of poly(3-hydroxybutyrate) scaffold affects cell-material interactions? J Biomed Mater Res A 2012;100 (7):1907-18.

8. Misra SK, Valappil SP, Roy I, Boccaccini AR. Polyhydroxyalkanoate (PHA)/inorganic phase composites for tissue engineering applications. Biomacromolecules 2006;7(8):2249-58.

9. Tong H-W, Wang M, Lu WW. Electrospinning and evaluation of PHBVbased tissue engineering scaffolds with different fibre diameters, surface topography and compositions. J Biomater Sci Polym Ed 2011:37-41.

10. Deng Y, Lin X-S, Zheng Z, Deng J-G, Chen J-C, Ma H, et al. Poly (hydroxybutyrate-co-hydroxyhexanoate) promoted production of extracellular matrix of articular cartilage chondrocytes in vitro. Biomaterials 2003;24(23):4273-81.

11. Ma G, Yang D, Wang K, Han J, Ding S, Song G, et al. Organic-soluble chitosan/polyhydroxybutyrate ultrafine fibers as skin regeneration prepared by electrospinning. J Appl Polym Sci 2010;118:3619-24.

12. Ghasemi-Mobarakeh L, Prabhakaran MP, Morshed M, Nasr-Esfahani MH, Ramakrishna S. Bio-functionalized PCL nanofibrous scaffolds for nerve tissue engineering. Mater Sci Eng C 2010;30(8):1129-36 [Elsevier B.V.].

13. Meng W, Kim S-Y, Yuan J, Kim JC, Kwon OH, Kawazoe N, et al. Electrospun PHBV/collagen composite nanofibrous scaffolds for tissue engineering. J Biomater Sci Polym Ed 2007;18(1):81-94.

14. Nitschke M, Schmack G, Janke A, Simon F, Pleul D, Werner C. Low pressure plasma treatment of poly (3-hydroxybutyrate): toward tailored polymer surfaces for tissue engineering scaffolds. J Biomed Mater Res 2001;59(4):632-8

15. Pompe T, Keller K, Mothes G, Nitschke M, Teese M, Zimmermann R, et al. Surface modification of poly(hydroxybutyrate) films to control cell-matrix adhesion. Biomaterials 2007;28(1):28-37.

16. Zhijiang C, Guoxiang C, Mingming G, Zhiyuan T. Surface modification of poly(3-hydroxybutyrate) (PHB) by photografting and its properties evaluation. J Polym Res 2004;11(2):99-104.

17. Shen F, Zhang E, Wei Z. Surface bio-modification of poly(hydroxybutyrate-co-hydroxyhexanoate) and its aging effect. Colloids Surf B: Biointerfaces 2009;73(2):302-7.

18. Tesema Y, Raghavan D, Stubbs J. Bone cell viability on collagen immobilized poly(3-hydroxybutrate-co-3-hydroxyvalerate) membrane: effect of surface chemistry. J Appl Polym Sci 2004;93(5):2445-53.

19. Baek J-Y, Xing Z-C, Kwak G, Yoon K-B, Park S-Y, Park LS, et al. Fabrication and characterization of collagen-immobilized porous PHBV/HA nanocomposite scaffolds for bone tissue engineering. $J$ Nanomater 2012;2012:1-11.

20. Hu S-G, Jou C-H, Yang M. Protein adsorption, fibroblast activity and antibacterial properties of poly(3-hydroxybutyric acid-co-3-hydroxyvaleric acid) grafted with chitosan and chitooligosaccharide after immobilized with hyaluronic acid. Biomaterials 2003;24(16):2685-93.

21. Armstrong SJ, Wiberg M, Terenghi G, Kingham PJ. ECM molecules mediate both Schwann cell proliferation and activation to enhance neurite outgrowth. Tissue Eng 2007;13(12):2863-70.
22. Williams DF. The role of short synthetic adhesion peptides in regenerative medicine; the debate. Biomaterials 2011;32(18):4195-7 [Elsevier Ltd.].

23. Wang Y-Y, Lü L-X, Shi J-C, Wang H-F, Xiao Z-D, Huang N-P. Introducing RGD peptides on PHBV films through PEG-containing cross-linkers to improve the biocompatibility. Biomacromolecules 2011;12(3):551-9.

24. Masaeli E, Morshed M, Nasr-Esfahani MH, Sadri S, Hilderink J, van Apeldoorn A, et al. Fabrication, characterization and cellular compatibility of poly(hydroxy alkanoate) composite nanofibrous scaffolds for nerve tissue engineering. PLoS One 2013;8(2):e57157.

25. Sill TJ, von Recum HA. Electrospinning: applications in drug delivery and tissue engineering. Biomaterials 2008;29(13):1989-2006.

26. Matthews JA, Wnek GE, Simpson DG, Bowlin GL. Electrospinning of collagen nanofibers. Biomacromolecules 2002;3(2):232-8.

27. Thiré RMSM, Meiga TO, Dick S, Andrade LR. Functionalization of biodegradable polyester for tissue engineering applications. Macromol Symp 2007;258(1):38-44.

28. Yang X, Zhao K, Chen G-Q. Effect of surface treatment on the biocompatibility of microbial polyhydroxyalkanoates. Biomaterials 2002;23(5):1391-7.

29. Zhang D, Cui F, Luo Z, Lin Y, Zhao K, Chen G. Wettability improvement of bacterial polyhydroxyalkanoates via ion implantation. Surf Coat Technol 2000;131:350-4.

30. Mattanavee W, Suwantong O, Puthong S, Bunaprasert T, Hoven VP, Supaphol P. Immobilization of biomolecules on the surface of electrospun polycaprolactone fibrous scaffolds for tissue engineering. ACS Appl Mater Interfaces 2009;1(5):1076-85.

31. Gupta D, Venugopal J, Prabhakaran MP, Dev VRG, Low S, Choon AT, et al. Aligned and random nanofibrous substrate for the in vitro culture of Schwann cells for neural tissue engineering. Acta Biomater 2009;5 (7):2560-9 [Acta Materialia Inc.].

32. Jahani H, Kaviani S, Hassanpour-Ezatti M, Soleimani M, Kaviani Z, Zonoubi $Z$. The effect of aligned and random electrospun fibrous scaffolds on rat mesenchymal stem cell proliferation. Cell J 2012;14(1):31-8.

33. Wang HB, Mullins ME, Cregg JM, McCarthy CW, Gilbert RJ. Varying the diameter of aligned electrospun fibers alters neurite outgrowth and Schwann cell migration. Acta Biomater 2010;6(8):2970-8.

34. Griffin J, Delgado-Rivera R, Meiners S, Uhrich KE. Salicylic acid-derived poly(anhydride-ester) electrospun fibers designed for regenerating the peripheral nervous system. J Biomed Mater Res A 2011;97A(3):230-42.

35. Wang W, Itoh S, Konno K, Kikkawa T, Ichinose S, Sakai K, et al. Effects of Schwann cell alignment along the oriented electrospun chitosan nanofibers on nerve regeneration. $J$ Biomed Mater Res A 2009;91(4):994-1005.

36. Huang C, Chen R, Ke Q, Morsi Y, Zhang K, Mo X. Electrospun collagen-chitosan-TPU nanofibrous scaffolds for tissue engineered tubular grafts. Colloids Surf B: Biointerfaces 2011;82(2):307-15.

37. Sangsanoh P, Waleetorncheepsawat S, Suwantong O, Wutticharoenmongkol $\mathrm{P}$, Weeranantanapan $\mathrm{O}$, Chuenjitbuntaworn $\mathrm{B}$, et al. In vitro biocompatibility of Schwann cells on surfaces of biocompatible polymeric electrospun fibrous and solution-cast film scaffolds. Biomacromolecules 2007;8(5):1587-94.

38. Li B, Chen J, Wang JH. RGD peptide-conjugated poly(dimethylsiloxane) promotes adhesion, proliferation, and collagen secretion of human fibroblasts. J Biomed Mater Res A 2006;79A(4):989-98.

39. Koh HS, Yong T, Chan CK, Ramakrishna S. Enhancement of neurite outgrowth using nano-structured scaffolds coupled with laminin. Biomaterials 2008;29(26):3574-82.

40. Ghasemi-Mobarakeh L, Prabhakaran MP, Morshed M, Nasr-Esfahani M-H, Ramakrishna S. Electrospun poly(epsilon-caprolactone)/gelatin nanofibrous scaffolds for nerve tissue engineering. Biomaterials 2008;29 (34):4532-9.

41. Ren Y-J, Zhang H, Huang H, Wang X-M, Zhou Z-Y, Cui F-Z, et al. In vitro behavior of neural stem cells in response to different chemical functional groups. Biomaterials 2009;30(6):1036-44 [Elsevier Ltd.]. 
42. Pritchard CD, Arnér KM, Neal RA, Neeley WL, Bojo P, Bachelder E, et al. The use of surface modified poly(glycerol-co-sebacic acid) in retinal transplantation. Biomaterials 2010;31(8):2153-62.

43. Snipes GJ, Suter U, Welcher AA, Shooter EM. Characterization of a novel peripheral nervous system myelin protein (PMP-22/SR13). J Cell Biol 1992;117(1):225-38.

44. Feng S, Shen X, Fu Z, Shao M. Preparation and characterization of gelatinpoly(L-lactic) acid/poly(hydroxybutyrate-co-hydroxyvalerate) composite nanofibrous scaffolds. J Macromol Sci Part B 2011 Sep;50(9):1705-13.

45. Chew SY, Mi R, Hoke A, Leong KW, Yian S. The effect of the alignment of electrospun fibrous scaffolds on Schwann cell maturation. Biomaterials 2008;29(6):653-61.

46. Yuan Q, Liao D, Yang X, Li X, Wei N, Tan Z, et al. Effect of implant surface microtopography on proliferation, neurotrophin secretion, and gene expression of Schwann cells. J Biomed Mater Res A 2010;93A (1):381-8.

47. Johnson EO, Charchanti A, Soucacos PN. Nerve repair: experimental and clinical evaluation of neurotrophic factors in peripheral nerve regeneration. Injury 2008;39(Suppl 3):S37-42.

48. Cai X, Luo E, Yuan Q. Interaction between Schwann cells and osteoblasts in vitro. Int J Oral Sci 2010;2(2):74-81.

49. Tosaki T, Kamiya H, Yasuda Y, Naruse K, Kato K, Kozakae M, et al. Reduced NGF secretion by Schwann cells under the high glucose condition decreases neurite outgrowth of DRG neurons. Exp Neurol 2008;213(2):381-7.

50. Gao C, Ma S, Ji Y, Wang J, Li J. Siatic nerve regeneration in rats stimulated by fibrin glue containing nerve growth factor: an experimental study. Injury 2008;39(12):1414-20. 